\title{
Crystallographic Texture Study in Melt-Spun Pr-Fe-B 2:14:1 Based Nanocomposite Magnet
}

\author{
Y. Zhang, Z. Q. Jin, H. L. Wang, and G. C. Hadjipanayis \\ Department of Physics \& Astronomy, University of Delaware, Newark, DE 19176
}

Exchange-coupled nanocomposites have attracted considerable attention due to their potential application for high performance permanent magnets [1,2]. The melt-spinning method is a potential way to fabricate anisotropic nanocomposite magnets. The microstructural changes that occur in melt-spun ribbons during solidification, especially, from the contact side (wheel side or roll side) to the free surface of the ribbons can give rise to a preferred orientation. Thus, crystallographic texture may be introduced into the ribbon samples, which may lead to the formation of anisotropic nanocomposite magnets, with much improved magnetic properties [3, 4].

In this work, both TEM and SEM were used to study the microstructure and crystallographic texture of $\operatorname{Pr}_{2} \mathrm{Fe}_{14} \mathrm{~B}_{2}$ based nanocomposite magnets. $\operatorname{Pr}_{7} \mathrm{~Tb}_{1} \mathrm{Fe}_{87} \mathrm{Nb}_{0.5} \mathrm{Zr}_{0.5} \mathrm{~B}_{4}$ ribbons were fabricated by melt spinning at substrate velocity of $14 \mathrm{~m} / \mathrm{s}$ and subsequently annealed at $700^{\circ} \mathrm{C}$ for $10 \mathrm{~min}$. TEM samples were prepared by ion milling and SEM samples were polished and then etched. SEM crosssection images of $\operatorname{Pr}_{7} \mathrm{~Tb}_{1} \mathrm{Fe}_{87} \mathrm{Nb}_{0.5} \mathrm{Zr}_{0.5} \mathrm{~B}_{4}$ ribbons spun at $14 \mathrm{~m} / \mathrm{s}$ are shown in figure 1. Three feature regions appear on cross-sectioned as-spun samples: (i) a narrow region (5.5 $\mu \mathrm{m}$ width) with fine structure at the contact side; (ii) a columnar region (3-4 $\mu \mathrm{m}$ width) with big grains; (iii) an equiaxed structure region with about $17 \mu \mathrm{m}$ width at the free surface side. There are clear interfaces among these regions, indicating a large temperature gradient during the melt-spinning process. Elemental profile shows a uniform distribution of composition across the cross-section of the asspun ribbon. After annealing, the microstructure of cross-sectioned samples becomes uniform (figure $1 \mathrm{~b}$ ). The depth of the region close to the contact side diminished tobe about $2.5 \mu \mathrm{m}$, and the columnar region disappears completely. A textured electron diffraction pattern was taken from the free surface of as-spun ribbon samples (TEM sample was only ion-milled on the contact side) (figure 2a). Figure $2 \mathrm{~b}$ gives the DF image of the textured grains taken from a bright portion of $(006)_{2: 14: 1}$ ring. It means that the crystallographic texture is originated from 2:14:1 grains, which is consistent with our X-ray results [5]. However, there is no texture feature on the electron diffraction pattern taken from the contact side of as-spun ribbon sample (figure 3a), although a nanocrystalline structure is observed in this sample (figure 3b). For the annealed ribbon samples, TEM confirmed that no crystallographic texture structure was found on both the free side and the contact side. It is concluded that the anisotropy is associated with a crystallographic texture formed in $\operatorname{Pr}_{2} \mathrm{Fe}_{14} \mathrm{~B}_{2} / \alpha-\mathrm{Fe}$ nanocomposites during melt-spinning, which possibly is originated from the non-uniform morphology across the cross-section of the ribbons [6].

\section{References}

[1] R. Skomski et al., Phys. Rev. B. 48 (1993) 15812.

[2] Y. Zhang et al., Appl. Phys. Lett. 79 (2001) 797.

[3] Kojima et al., Scripta Mater. 44 (2001) 1383.

[4] Y.R. Wang et al., J. Appl. Phys. 81 (1997) 4450.

[5] Z. Q. Jin et al., DARPA-Meta-Materials Program Research Report. (2002).

[6] Supported by DARPA-Meta-Materials Program under Grant No.F33615-01-2-2166. 


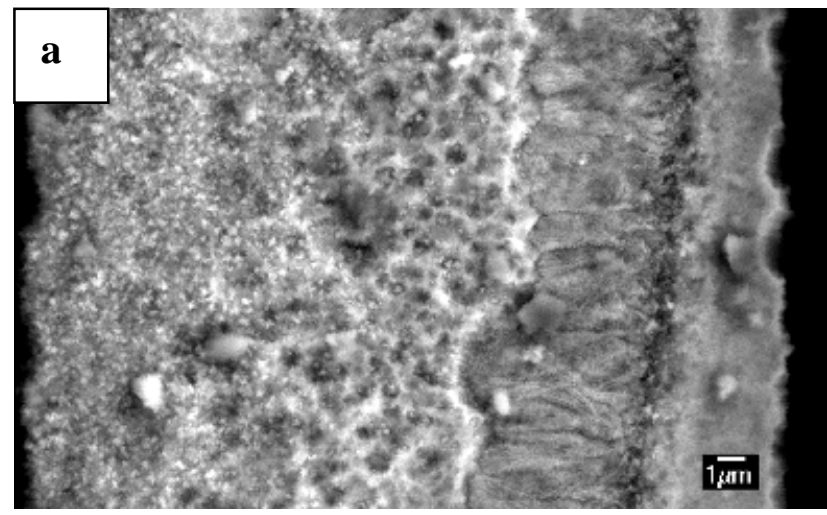

Free side

Contact side

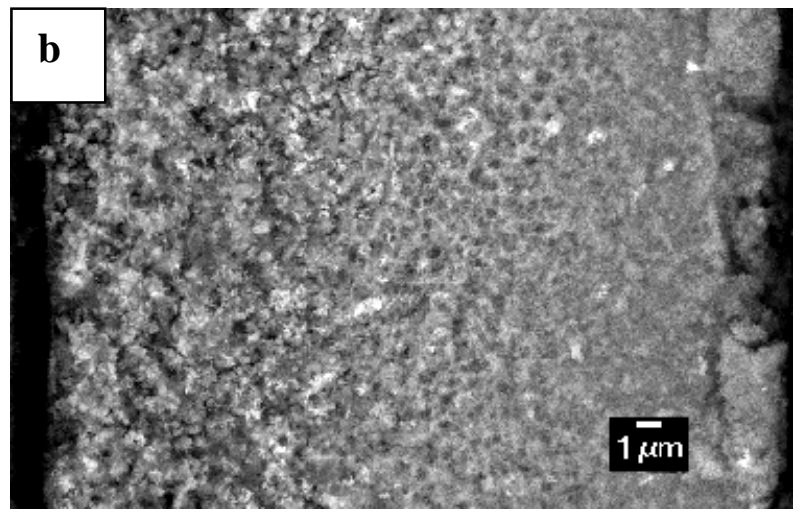

Free side

Contact side

FIG. 1. SEM cross-section images of $\operatorname{Pr}_{7} \mathrm{~Tb}_{1} \mathrm{Fe}_{87} \mathrm{Nb}_{0.5} \mathrm{Zr}_{0.5} \mathrm{~B}_{4}$ ribbons spun at $14 \mathrm{~m} / \mathrm{s}$ : (a) As-spun; (b) Annealed at $700^{\circ} \mathrm{C}$ for $10 \mathrm{~min}$.
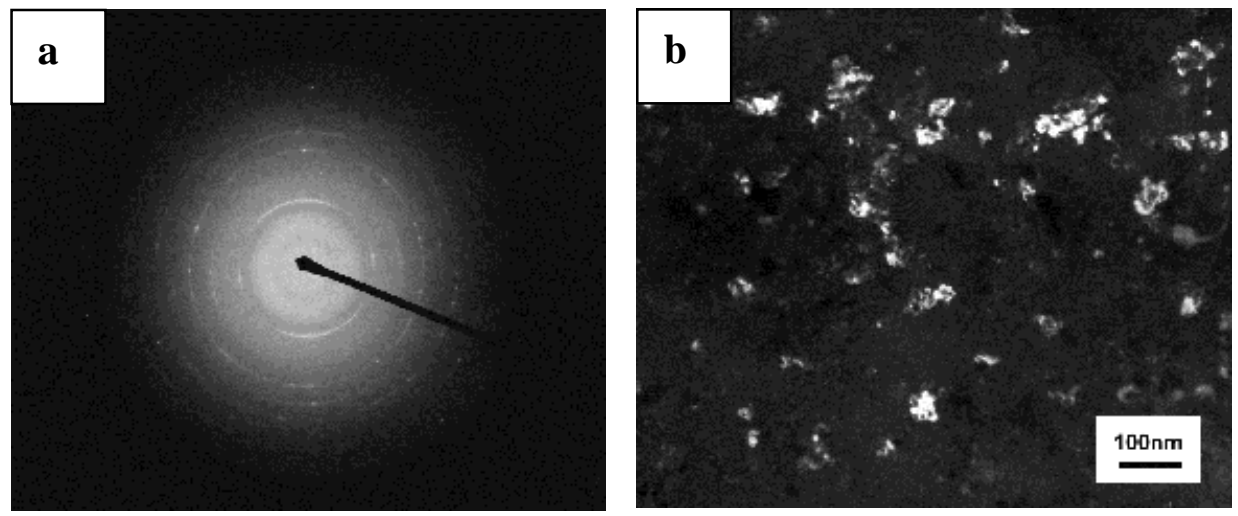

FIG. 2. TEM microstructure of the free surface of as-spun ribbon samples: (a) Electron diffraction pattern; (b) DF image of the textured grains taken from a bright portion of $(006)_{2: 14: 1}$ ring.
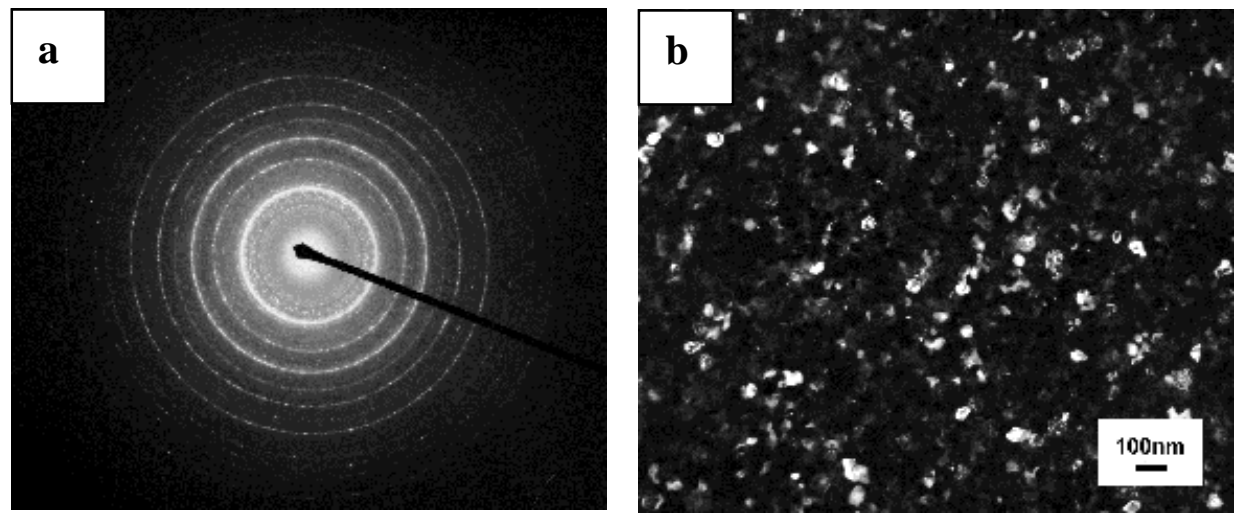

FIG. 3. TEM microstructure of the contact side of as-spun ribbon samples: (a) Electron diffraction pattern; (b) BF image showing the nanocrystalline structure. 